\title{
18 months sliced off Celebrex's patent protection
}

A US district court has invalidated a patent (US RE 44048) that describes methods of using Celebrex (celecoxib) to treat inflammatory disorders. This means that patent protection for the cyclooxygenase 2 (COX2) inhibitor will now finish at the end of May 2014, potentially allowing generics manufacturers to muscle in 18 months earlier than originally anticipated. Given that Celebrex had worldwide revenues of US $\$ 2.92$ billion in 2013, this is a big loss for Pfizer.

Prior to this case, Pfizer owned three key patents that protect Celebrex, two of which expire at the end of May 2014, and the '048 patent, which was due to expire early in December 2015. A dispute between Pfizer and several generics companies kicked off in 2008 over the validity of the Celebrex patents, which resulted in a US appeals court invalidating a patent (US 5760068; entitled "Substituted pyrazolyl benzenesulfonamides for the treatment of inflammation") that was a precursor to the ' 048 patent. The ' 068 patent was invalidated on grounds of 'obviousness-type double patenting', meaning that the claims in this patent overlapped with claims in the other Celebrex patents.
To try to overcome this setback, Pfizer then sought to have the ' 068 patent reissued by the US Patent and Trademark Office; this procedure exists to allow patentees to correct an error in a patent. This request was successful, resulting in the issuance of the '048 patent (entitled "4-[5-(4-methylphenyl)3-(trifluoromethyl)-1H-pyrazol-1-YL] benzenesulfonamide for the treatment of inflammation or an inflammation-associated disorder").

Following issuance of the patent, the current round of litigation commenced between Pfizer and the same generics companies - Lupin, Teva, Mylan, Apotex and Actavis that wished to market generics upon cessation of the patents that will expire in May 2014. Pfizer asserted that the ' 048 patent overcame the rejection of obviousness-type double patenting because of the narrower claims of the ' 048 patent compared to the ' 068 patent.

But the court found that the issue of obviousness-type double patenting was not mitigated. Notably, there are two types of applications that can be filed to request a reissued patent: a divisional application (which should be filed when the original parent patent contains more than one distinct invention) and a continuation application (which should be filed when the applicant wishes to modify the claims of their patent). In line with these requirements, Pfizer had filed a continuation application.

The court noted that although divisional applications are protected against obviousness-type double patenting - largely because the amendments are made at the request of the patent office - continuations (which are initiated by the patentee) are not exempt. Therefore, the ' 048 patent was not shielded from obviousness-type double patenting, and was deemed invalid because of the overlap with other Celebrex patents. In a statement, Pfizer says that it will appeal the decision.

Searle and Pfizer versus Lupin et al.: case number 2:13cv121 (US District Court for the Eastern district of Virginia)

Charlotte Harrison

\section{PATENT ADVISORS}

Daniel M. Becker: Dechert, Mountain View, CA, USA. Luke Kempton: Wragge \& Co., London, UK. Leslie Meyer-Leon: IP Legal Strategies, Boston, MA, USA. George W. Schlich: Schlich \& Co., London, UK. John A. Tessensohn: Shusaku Yamamoto, Osaka, Japan. Philip Webber: Dehns, London, UK. 